\title{
LUMPY DEMAND FORECASTING USING LINEAR EXPONENTIAL SMOOTHING, ARTIFICIAL NEURAL NETWORK, AND BOOTSTRAP
}

\author{
Sinta Rahmawidya Sulistyo, Alvian Jonathan Sutrisno \\ Mechanical and Industrial Engineering Department, Faculty of Engineering \\ Universitas Gadjah Mada \\ Jalan Grafika 2, Yogyakarta \\ sinta.sulistyo@ugm.ac.id
}

\begin{abstract}
Lumpy demand represents the circumstances when a demand for an item has a large proportion of periods having zero demand. This certain situation makes the time series methods might become inappropriate due to the model's inability to capture the demand pattern. This research aims to compare several forecasting methods for lumpy demand that is represented by the demand of spare part. Three forecasting methods are chosen; Linear Exponential Smoothing (LES), Artificial Neural Network (ANN), and Bootstrap. The Mean Absolute Scaled Error (MASE) is used to measure the forecast performance. In order to gain more understanding on the effect of the forecasting method on spare parts inventory management, inventory simulation using oil and gas company's data is then conducted. Two inventory parameters; average inventory and service level; are used to measure the performance. The result shows that ANN is found to be the best method for spare part forecasting with MASE of 0,761. From the inventory simulation, the appropriate forecasting method on spare parts inventory management is able to reduce average inventory by 11,9\% and increase service level by 10,7\%. This result justifies that selecting the appropriate forecasting method is one of the ways to achieve spare part inventory management's goal.
\end{abstract}

Keywords: forecasting; inventory management; lumpy demand; spare part

\section{Introduction}

Intermittent demand is a random, sporadic demand pattern, which occurs periods of zero and also periods with a constant quantity of demand (Syntetos and Boylan, 2005). Silver (1981) states that an item has a lumpy demand means that it has some period of zero demand. Syntetos and Boylan (2005) define intermittent demand more specifically based on the Square of The Coefficient of Variation $\left(\mathrm{CV}^{2}\right)$ and Average Demand Interval (ADI). The intermittent demand makes demand's pattern becomes difficult to identify. Therefore, timeseries methods based on identifying demand's pattern such as moving average, exponential smoothing, and ARIMA might be inappropriate to use.

Croston (1972) is one of the pioneers to develop forecasting method for intermittent demand with his widely known Croston's method (CR). The development of CR gives a general idea for intermittent demand forecasting which is to use two separate estimators: the probability of demand's occurrence; and the demand's magnitude. However, the shortcoming of the model is that a bias is found on the CR's estimator. Syntetos (2001) with SY model and Syntetos and Boylan (2005) with SBA (Syntetos-Boylan Approximation) model aims to modify the model to remedy the shortcoming. 
The bias-free method still has another shortcoming. The model still cannot represent the obsolescence - a typical spare part's characteristic. Teunter et al (2011), Prestwich (2013), and Prestwich (2014) suggest some modification to alleviate its shortcomings such as Teunter, Syntetos, and Babai (TSB); Hyperbolic Exponential Smoothing (HES); and Linear Exponential Smoothing (LES).

Artificial Neural Network (ANN) has been used for prediction and forecasting but the application of ANN to forecast intermittent or lumpy demand is not easy to be found. Gutierrez et al (2008) used Feed-Forward Neural Network with Back Propagation to forecast electronic goods with lumpy demand. ANN is being compared with exponential smoothing and SBA. ANN gives the least error on all three error parameters; Mean Absolute Percentage Error (MAPE), Percentage Best (PB), and Relative Geometric Root Mean Square Error (RGRMSE),

On the non-parametric side, Willemain, et al (2004) proposed a new approach to the intermittent demand forecasting using the bootstrap. Willemain, et al (2004) modified the bootstrap using the first order Markov chain to predict the demand. Willemain, et al (2004) used the method to forecast the intermittent demand of the airplane, electronic, and service parts. A comparison of Bootstrap, CR, and exponential smoothing is conducted and bootstrap has the lowest MAPE as the error measurement.

One typical example of intermittent demand is spare part demand. It is important that the spare part needs to be well-managed since spare part becomes one of the critical components in the maintenance, repair, and overhaul (MRO) process. It should be available when a failure occurs so that there will be no delay in repairing process due to the lack of spare parts (Rego and Mesquita, 2011). This makes the inventory decision related with the spare part is a challenging task for practitioners. Moreover, the nature of spare part's demand which is usually lumpy or intermittent is another challenge for good inventory management.

With the various developments of intermittent or lumpy demand forecasting method, the urge to find the best method from all development emerges. This research intends to find the best method to forecast lumpy demand and its effect on the inventory management.

\section{Data and Forecasting Methods}

\subsection{Dataset}

In this research, the lumpy and intermittent dataset are taken from the demand of the spare parts in an oil and gas company. The dataset consists of 21 items of spare parts with 36 points of monthly observations for each spare part. The correlation test is conducted to confirm that each spare part was used independently.

Spare parts are then categorized into two groups based on demand's type with two parameters; Square of The Coefficient of Variation $\left(\mathrm{CV}^{2}\right)$ and Average Demand Interval (ADI) as proposed by Syntetos and Boylan (2005). Based on the value of $\mathrm{CV}^{2}$ and ADI, there are 18 spare parts or $87,5 \%$ of spare parts that categorized as lumpy demand and the rest, for 3 spare parts or $14,3 \%$ of spare parts, categorized as intermittent demand.

\subsection{Linear Exponential Smoothing}

Prestwich et al (2014) proposed new modification of CR called Linear Exponential Smoothing (LES) to remedy its shortcoming from previous modified method. It has the same basic mechanism as CR to forecast demand but is proven to be bias-free. LES is one of the few forecasting method that can represent obsolescene of spare part. It uses exponential smothing with linear decay so that when item has no demand at all after a certain period of time, LES forces the forecast demand to be zero. To forecast with LES, equation 1 to equation 6 is used. Smoothing constant alpha and beta are optimised to give the least error on 
training dataset. They are kept between 0,5 to 0,95 so that it will not give smoothing constant of 0 which means naive forecasting.

$$
\begin{gathered}
\text { If } Y_{t}>0 \quad \hat{Y}_{t+1}=\alpha Y_{t}+\alpha(1-\alpha) \hat{Y}_{t}+\alpha(1-\alpha)^{2} \hat{Y}_{t-1}+\cdots \\
\widehat{T}_{t+1}=\beta T_{t}+\beta(1-\beta) \widehat{T}_{t}+\beta(1-\beta)^{2} \widehat{T}_{t-1}+\cdots \\
\hat{Y}_{t+1}=\frac{\hat{Y}_{t+1}}{\widehat{T}_{t+1}} \\
T_{t}=1
\end{gathered}
$$

\subsection{Artificial Neural Network Model}

A proven neural network model proposed by Gutierrez et al (2008) is used in this research with some modifications. The type of neural network is the most widely used multilayered perceptron or feed-forward neural network trained by a back-propagation. The ANN consists of three layer MLP: one input layer, one hidden unit layer, and one output layer. The difference from ANN used in Gutierrez et al (2008) is the algorithm of learning process. Levenberg-Marquardt algorithm is used for efficient learning.

Problems that often occurs on ANN training are being trapped in local minima and the overfitting on dataset. Overfitting occurs when the error on training dataset decreases but the error on testing dataset increases. In order to avoid being trapped in local minima, simultaneous learning proposed by Atakulreka and Sutivong (2007) is used and that gives every dataset five networks. An attempt to find the optimal number of training to avoid overfitting is conducted by training fifteen network up to thirty times. The error from training dataset and testing dataset are recorded for the whole process. From this result, five times and fifteen times training are found not to overfit the data. The summary of this attempt can be found in Table 1. With five networks and two different configurations of training's number,

\begin{tabular}{|c|c|c|c|c|}
\hline $\begin{array}{c}\text { Number of } \\
\text { Training }\end{array}$ & $\begin{array}{c}\text { Frequency } \\
\text { Testing Error } \\
\text { Do Not Move }\end{array}$ & $\begin{array}{c}\text { Frequency } \\
\text { Testing Error } \\
\text { Increases }\end{array}$ & $\begin{array}{c}\text { Frequency } \\
\text { Testing Error } \\
\text { Decreases }\end{array}$ & Interpretation \\
\hline 1 to 5 & 8 & 2 & 5 & No Overfit \\
\hline 5 to 10 & 11 & 2 & 2 & Overfit \\
\hline 10 to 15 & 9 & 2 & 4 & No Overfit \\
\hline 15 to 20 & 11 & 2 & 2 & Overfit \\
\hline 20 to 25 & 11 & 3 & 1 & Overfit \\
\hline 25 to 30 & 13 & 1 & 1 & Overfit \\
\hline
\end{tabular}
ten forecast configuration are generated for each dataset. Forecast configuration that gives the least error on training dataset is selected for forecasting on testing dataset.

Table 1. Attempt to Avoid Overfitting 


\subsection{Bootstrap}

Third method that is used in this research is Bootstrap. Bootstrap is used to construct empirical distribution function for the demand's magnitude. It is complimented with firstorder markov chain to forecast the sequence of demand. The modified bootstrap used in this research derived from model proposed by Willemain et al (2004). There are some modification on the model used in this research compared to model proposed by Willemain et al (2004) because of some limitations. Bootstrap model in this research uses 100 sampling with replacement and do not jitter the demand's magnitude. Example of first-order markov chain matrix probability and empirical distribution can be found in Table 2 and Table 3.

Table 2. First Order Markov Chain Matrix Probability

\begin{tabular}{llccc}
\hline \multicolumn{1}{c}{ From } & \multicolumn{1}{c}{ To } & Frequency & PDF & CDF \\
\hline Demand & Demand & 0 & 0 & 0 \\
Demand & No Demand & 4 & 1 & 1 \\
No Demand & Demand & 4 & 0,22 & 0,22 \\
No Demand & No Demand & 14 & 0,78 & 1 \\
\hline
\end{tabular}

Table 3. Empirical Distribution

\begin{tabular}{cccc}
\hline Demand's Magnitude & Frequency & PDF & CDF \\
\hline 50 & 27 & 0,267326733 & 0,267327 \\
125 & 43 & 0,425742574 & 0,693069 \\
200 & 31 & 0,306930693 & 1 \\
\hline
\end{tabular}

\subsection{Accuracy Metrics}

There are numerous ways to measure forecast error. The zero demand that occurs in intermittent or lumpy demand makes some forecast measurements become inappropriate. To measure which forecast perform the best, Mean Absolute Scaled Error (MASE) proposed by Hyndman (2006) is used. MASE is scale-free so that the result is independent of the scale of data. The basic notion of MASE is comparing between the error of proposed forecast method and error of naive method in training dataset. To compute MASE, Equation 7 and Equation 8 are used.

$$
q_{t}=\frac{e_{t}}{\frac{1}{n-1} \sum_{i=2}^{n}\left|\gamma_{i}-\gamma_{i-1}\right|}
$$

with:

$$
\begin{aligned}
& e_{i}=\text { error at } \mathrm{t} \text { period } \\
& \mathrm{n}=\text { number of data in training dataset } \\
& Y_{i}=\text { demand at i period in training dataset } \\
& \quad \text { MASE }=\operatorname{mean}\left(\left|q_{t}\right|\right)
\end{aligned}
$$

\subsection{Inventory Metrics}

Another way to look at forecasting method's performance is inventory parameter. By using inventory parameter, the effect of using appropriate forecasting method in inventory management can be perceived. Two inventory parameters: average inventory and fill rate are used. 


\section{Results and Discussion}

Twenty one datasets of spare part are categorized by demand's type. From 21 spare part, 18 spare parts are categorized to have lumpy demand and the other 3 spare parts have intermittent demand. To avoid contamination of result that is caused by difference of demand's type, lumpy demand spare parts that made up to $85,7 \%$ of total spare part are chosen to be focus of this research.

The next step is to forecast the lumpy demand spare parts with LES, ANN, and Bootstrap. MASE from testing dateset of each forecasting method is compared and ranked to find the best method which gives the least MASE. ANN with MASE of 0,761 is the best method for lumpy demand forecasting, followed by Bootstrap with MASE of 0,817, and LES ranks last with MASE of 0,931 . Table 4 shows MASE of each spare part for each forecasting method.

Table 4. MASE Forecasting Method

\begin{tabular}{cccc}
\hline Part Number & LES & ANN & Bootstrap \\
\hline 1 & 1,258 & 0,929 & 1,355 \\
2 & 0,393 & 0,297 & 0,350 \\
3 & 0,801 & 0,720 & 0,781 \\
4 & 0,663 & 0,594 & 0,646 \\
5 & 0,622 & 0,433 & 0,429 \\
6 & 0,438 & 0,406 & 0,444 \\
7 & 2,038 & 1,380 & 1,542 \\
8 & 0,750 & 0,717 & 0,662 \\
9 & 1,685 & 0,714 & 1,071 \\
10 & 2,395 & 2,210 & 1,806 \\
11 & 0,186 & 0,230 & 0,198 \\
12 & 0,059 & 0,070 & 0,120 \\
13 & 0,459 & 0,441 & 0,467 \\
14 & 1,103 & 1,030 & 0,962 \\
15 & 2,238 & 2,140 & 2,194 \\
16 & 0,821 & 0,745 & 0,825 \\
17 & 0,738 & 0,490 & 0,662 \\
18 & 0,116 & 0,155 & 0,185 \\
Mean & 0.931 & 0,761 & 0,817 \\
Rank & 3 & 1 & 2 \\
\hline
\end{tabular}

To give a good look of effect of forecasting method on inventory management, inventory simulation is conducted. The inventory simulation uses actual policy that is applied by company where the data is gathered. Therefore, the number of planned buying can be made in a year is one which is on the first month of the year. The demand forecast is used to determine the quantity of spare part to buy on planned buying. In order to give idea on company's inventory, actual method that buy quantity of spare part based on yearly average demand is used on another inventory simulation. The performance of forecasting method is reviewed by two inventory parameters: average inventory and fill rate. The result of inventory simulation can be found on Table 5 and Table 6 . 
Table 5. Average Inventory Parameter

\begin{tabular}{ccccc}
\hline Part Number & LES & Bootstrap & ANN & Actual \\
\hline 1 & 17,214 & 65,071 & 17,929 & 29,785 \\
2 & 64 & 31,429 & 59,714 & 142,857 \\
3 & 40,143 & 5,286 & 58,786 & 27,857 \\
4 & 6,429 & 14,857 & 18,078 & 41,285 \\
5 & 2,071 & 0,429 & 6,500 & 11,785 \\
6 & 8,143 & 1,357 & 51 & 27 \\
7 & 8,143 & 16,357 & 8,357 & 9,214 \\
8 & 44,429 & 109,571 & 86,714 & 124,642 \\
9 & 20,857 & 30,071 & 100,714 & 117 \\
10 & 5,857 & 4,714 & 23,571 & 6,857 \\
11 & 0 & 2,143 & 84,143 & 423,571 \\
12 & 76,714 & 139,286 & 80,143 & 602,142 \\
13 & 347,428 & 25,714 & 74 & 264,285 \\
14 & 15,714 & 7,143 & 25,929 & 29,785 \\
15 & 0 & 4,571 & 8,357 & 6,142 \\
16 & 0,571 & 32,357 & 3 & 15,285 \\
17 & 3,643 & 3,643 & 9,643 & 13,071 \\
18 & 1,214 & 4,786 & 3,786 & 18,214 \\
\hline
\end{tabular}

Table 6. Service Level Parameter

\begin{tabular}{ccccc}
\hline Part Number & LES & Bootstrap & ANN & Actual \\
\hline 1 & 0,383 & 0,661 & 0,652 & 0,573 \\
2 & 0,765 & 0,765 & 0,765 & 0,765 \\
3 & 0,689 & 0,258 & 0,874 & 0,586 \\
4 & 0,536 & 0,982 & 1 & 1 \\
5 & 0,345 & 0,103 & 0,655 & 0,655 \\
6 & 0,661 & 0,339 & 0,875 & 0,767 \\
7 & 0,381 & 0,612 & 0,333 & 0,360 \\
8 & 0,427 & 0,694 & 0,629 & 0,725 \\
9 & 0,183 & 0,3025 & 0,500 & 0,5 \\
10 & 0,281 & 0,226 & 0,808 & 0,328 \\
11 & 0,183 & 0,056 & 0,611 & 0,611 \\
12 & 1 & 1 & 1 & 1 \\
13 & 0,714 & 0,643 & 0,714 & 0,714 \\
14 & 0,227 & 0,103 & 0,353 & 0,389 \\
15 & 0 & 0,139 & 0,239 & 0,186 \\
16 & 0,129 & 0,758 & 0,532 & 0,677 \\
17 & 0,333 & 0,333 & 0,762 & 0,523 \\
18 & 0,500 & 1 & 0,500 & 1 \\
\hline
\end{tabular}


After that, performance of forecasting method with respect to actual method is compared. Table 8 and Table 9 report the performance of forecasting method measured by average inventory and service level respectively.

Table 8. Average Inventory with Respect to Actual

\begin{tabular}{cccc}
\hline Part Number & $\begin{array}{c}\text { LES to } \\
\text { Actual }\end{array}$ & $\begin{array}{c}\text { Bootstrap to } \\
\text { Actual }\end{array}$ & $\begin{array}{c}\text { ANN to } \\
\text { Actual }\end{array}$ \\
\hline 1 & 0,578 & 2,185 & 0,602 \\
2 & 0,448 & 0,220 & 0,418 \\
3 & 1,426 & 0,188 & 2,089 \\
4 & 0,156 & 0,360 & 0,438 \\
5 & 0,176 & 0,036 & 0,552 \\
6 & 0,302 & 0,050 & 1,889 \\
7 & 0,884 & 1,775 & 0,907 \\
8 & 0,356 & 0,879 & 0,696 \\
9 & 0,178 & 0,257 & 0,861 \\
10 & 0,854 & 0,688 & 3,438 \\
11 & 0,066 & 0,005 & 0,199 \\
12 & 0,127 & 0,231 & 0,133 \\
13 & 1,315 & 0,097 & 0,280 \\
14 & 0,528 & 0,240 & 0,871 \\
15 & 0 & 0,744 & 1,360 \\
16 & 0,037 & 2,117 & 0,196 \\
17 & 0,279 & 0,279 & 0,738 \\
18 & 0,067 & 0,263 & 0,208 \\
\hline
\end{tabular}

Table 9. Service Level with Respect to Actual

\begin{tabular}{cccc}
\hline Part Number & $\begin{array}{c}\text { LES to } \\
\text { Actual }\end{array}$ & $\begin{array}{c}\text { Bootstrap } \\
\text { to Actual }\end{array}$ & $\begin{array}{c}\text { ANN to } \\
\text { Actual }\end{array}$ \\
\hline 1 & 0,667 & 1,152 & 1,136 \\
2 & 1 & 1 & 1 \\
3 & 1,175 & 0,439 & 1,489 \\
4 & 0,536 & 0,982 & 1 \\
5 & 0,526 & 0,158 & 1 \\
6 & 0,860 & 0,442 & 1,140 \\
7 & 1,057 & 1,698 & 0,925 \\
8 & 0,589 & 0,956 & 0,867 \\
9 & 0,365 & 0,605 & 1 \\
10 & 0,854 & 0,688 & 2,458 \\
11 & 0,955 & 0,091 & 1 \\
12 & 1 & 1 & 1 \\
13 & 1 & 0,900 & 1 \\
14 & 0,582 & 0,265 & 0,905 \\
15 & 0,000 & 0,744 & 1,279 \\
\hline
\end{tabular}




\begin{tabular}{cccc}
\hline 16 & 0,190 & 1,119 & 0,786 \\
17 & 0,636 & 0,636 & 1,455 \\
18 & 0,500 & 1 & 0,500 \\
\hline
\end{tabular}

The arithmetic mean of relative average inventory and service level for three forecasting method is computed and reported in Table 10. The result shows that LES reduce average inventory by $56,8 \%$ but service level is reduced by $30,6 \%$. Bootstrap's result gives the same pattern of that in LES' result which reduces average inventory by $41 \%$ and reduces service level by $22,9 \%$. Difference pattern is found in ANN's result. ANN reduces average inventory by $11,9 \%$ but increases service level by $10,7 \%$.

Table 10. Summary

\begin{tabular}{cccc}
\hline Parameter & $\begin{array}{c}\text { LES to } \\
\text { Actual }\end{array}$ & $\begin{array}{c}\text { Bootstrap } \\
\text { to Actual }\end{array}$ & $\begin{array}{c}\text { ANN } \\
\text { to } \\
\text { Actual }\end{array}$ \\
\hline $\begin{array}{c}\text { Service } \\
\text { level } \\
\text { Average } \\
\text { inventory }\end{array}$ & 0,694 & 0,771 & 1,107 \\
\hline
\end{tabular}

\section{Conclusion}

This research does not only gives information about the best forecasting method for lumpy demand, but also presents the effect of appropriate forecasting method on inventory management. Measured by three different parameters, the results show the superiority of ANN. On top of that, with the appropriate forecasting method, inventory can be reduced without sacrificing service level, which are inventory management's goals.

Limitation on this research is on the company policy's that is used in inventory simulation. Because the number of inventory depends on the mechanism of planned buying, it might give different result given different mechanism. Therefore, this encourages more study on the effect of mechanism of planned buying.

\section{Acknowledgments}

The research is funded by research grant from Department of Mechanical and Industrial Engineering, Faculty of Engineering, Universitas Gadjah Mada. 


\section{BIBLIOGRAPHY}

Croston, J.D., 1972, 'Forecasting and Stock Control for Intermittent Demands', Journal of the Operational Research Society, Vol.23, No.3, pp. 289-303.

Efron, B., 1979, 'Bootstrap Methods: Another Look At The Jackknife', The Annals of Statistics, Vol.7, No.1, pp. 1-26.

Garg, J., 2013, Maintenance: Spare Parts Optimization., Ecole Centrale Paris, France.

Gutierrez, S.R., Solis, A.O., and Mukhopadhyay, S., 2008, 'Lumpy Demand Forecasting Using Neural Networks', International Journal of Production Economics, Vol.111, No.2, pp. 409-420.

Hyndman, R.J., 2015. Another Look at Forecast Accuracy Metrics for Intermittent Demand, Foresight: The International Journal of Applied Forecasting, Vol.4, pp. 43-46.

Kourentzes, N., 2013, Intermittent Demand Forecasts with Neural Networks, International Journal of Production Economics, Vol.143, No.1, pp 198-206.

Prestwich, S.D., Tarim, S.A., Rossi, R., dan Hnich, B., 2013, Forecasting Intermittent Demand by Hyperbolic-Exponential Smoothing, International Journal of Forecasting, Vol.30, No.4, pp 928-933.

Prestwich, S.D., Tarim, S.A., Rossi, R., and Hnich, B., 2014, Intermittency and Obsolescence: a Croston Method with Linear Decay, Edinburgh.

PwC, 2017, Oil and Gas in Indonesia, PwC Indonesia, Jakarta.

Silver, E.A., 1981, 'Operations Research in Inventory Management: A Review and Critique', International Journal of Operations Research, Vol.29, No.4, pp. 628-645.

Syntetos, A.A., 2001, Forecasting of Intermittent Demand, Brunerl University, London.

Syntetos, A.A. and Boylan, J.E., 2005, 'The Accuracy of Intermittent Demand Estimates', International Journal of Forecasting, Vol.21, No.2, pp.303-314.

Syntetos, A.A. and Boylan, J.E., 2011, Service Parts Management: Demand Forecasting and Inventory Control, Springer, London.

Rego, J.R.d., Mesquita, M.A.d., Spare Parts Inventory Control: A Literature Review, Prodacuao, Vol.21, No.4, pp.656-666.

Teunter, R.H., Syntetos, A.A., and Babai, M.Z., 2011, 'Intermittent Demand: Linking Forecasting to Inventory Obsolescence', European Journal of Operational Research, Vol.214, No.3, pp.606-615.

Willemain, T.R., Smart, C.N., and Schwarz, H.F., 2004, 'A New Approach to Forecasting Intermittent Demand for Service Parts Inventories', International Journal of Forecasting, Vol. 20, pp. 375-387. 